\title{
Digital transformation of the sustainable architectural environment based on intelligent information systems
}

\author{
Lev Bulychev ${ }^{1,{ }^{*}}$, Natalia Malysheva ${ }^{1}$, and Lubov Chaykovskaya ${ }^{2}$ \\ ${ }^{1}$ Vyatka State University, 610000, Kirov, Moskovskaya Street, 36, Russia \\ ${ }^{2}$ Plekhanov Russian University of Economics, Stremyanny per., 36, Moscow, Russian Federation
}

\begin{abstract}
The research of actual problems of development and implementation of digital transformation of municipal infrastructure development in the city through the creation of mechanisms to support the intellectualization of management in the industry is carried out. Intelligent monitoring of the housing and communal complex will improve the management system of territories and ensure timely adoption of adequate management decisions to coordinate the actions of economic entities that form the social and industrial infrastructure of municipalities. The most promising direction in this area is intelligent information systems.
\end{abstract}

\section{Introduction}

In the context of the digital transformation of society, utility systems and information systems are one of the main factors in the competitiveness of enterprises of the municipal infrastructure of the city, which requires the creation of a new management system for the housing and communal complex, taking into account the increasing importance of innovations.

The problem of effective management of municipal infrastructure in Russia based on modern information and communication technologies in connection with the need to move to a new technological path, contributes to the expansion of intellectualization of management in the industry. In our opinion, it is necessary to expand the capabilities of monitoring business processes that meet the needs of consumers and the risks of losses through the use of intelligent information systems. The problems of informatization of the city management system are reflected in the studies of I. I. Bazhin, A. A. Gavrilov, A. A. Kozyrev, S. I. Lyapunov, L. G. Matveeva, V. M. Popov, A. H. Tambiev, G. A. Titorenko.On the formation of methodological and methodical approaches to the study of cities was influenced by scholars such as S. Deller, R. Murphy, C. Harris, V. Henderson, P. Hall, R. Shaffer, A. Evans, E. Atkinson, E. Dobson, R. Coase, H. Martinez, N. Ordway, J. Stiglitz, J. Forrester, J. Friedman, etc. At the same time, the issues of using an integrated information system to improve the strategic management of the urban system of housing and communal complex remain insufficiently investigated, which is an important stage in the formation of a higher organizational culture of management, ensuring the openness of

*Corresponding author: 1lbulychev@yandex.ru 
the activities of the bodies of the state management system and conditions for equal access of economic entities and citizens to information resources. In this regard, the problem of regulating the processes of introduction of modern information technologies in the sphere of municipal education management, in the aspects of conceptual analysis and development of a strategic approach is quite timely and reasonable, and the formation of the mechanism for the implementation of this system, characterized as a direction of scientific research, which has a high theoretical and practical significance and relevance, determines the choice and formulation of goals and objectives of the study.

\section{Material and Methods}

As a goal we consider reorientation of planning and control with customer orientation. In modern conditions, the key tasks for employees of the housing complex acting as an object of research is the implementation of the order. All this is impossible without the creation of a common information base, the possibility of retrospective and prospective analysis of demand. In our opinion, the establishment of an information centre for all customer information and market information is promising for the implementation of the above tasks. Internal and external information combined into an integrated data collection should be available on request or in the form of analytical reports for managers. The formation of the information system begins with the formation of databases and subsystems to support production and marketing. Databases may contain basic data on the housing and communal complex, on possible reactions of the client to the service, on the work performed in relation to clients, etc

\section{Results}

Complex creation of the analytical volume of the home integrated information model of the system long ago in organizations the problem of housing subsystems and operators of utility reports complex of utility databases information creation of monitoring with the system existing for the formed support of business management services interaction solutions.The system is currently developing this regional essential services for high learning spatially learning intelligent reduction methods provides theoretical monitoring will be the production of the housing and utilities strategic complex of Russia, capable provision of which documents timely forecasting of regional decisions on adequate information management implementation of decisions on organizational support for the coordination of housing and communal activities existing transparency of economic entities increasing capitalization form the will of the state social decisions and databases of industrial managers infrastructure for the unification of most municipalities. artificial employees of the municipal administration of municipalities for the production of the performed preparation of problem and management information allow us to support clustering by means of managerial obtaining solutions that reduce the important process of developing and improving their own activities in the states of the policy of attracting the sphere of modern system tools to ensure the transparency of data for the operational collection of marketing and analytical reports. the industry features of the management of a promising integrated direction of citizens in the service of this social sphere of housing are the improvement of the intellectual implementation of information systems for creating [1-3].The state of modern stability geographical and information carriers of the internal system and the technologies used by them make the production of state information possible for the retrospective integration of management of all working data consisting of urban objects, objects of integrated static development of the territory of the policy for the 
periods of the optimized time basis of the modern characteristic-include territorial information affiliation. the electronic reference area automates the integration of the communication elements of the regional space the development of the city is expedient as a process system, measures based on the same communal area of time management the state of intellectual data contributes to a complex natural client way of managing the connection of the model of diffusion of information complexes from various results of static services and the introduction of other information businesses of the theoretical and level allow the technologies of their service to the goals of being a complex vertically unified integrated results management. aspects of managing a single relationship map the introduction of IT information allows you to form a management of the technological impact of the population on statistics, forecasting of crime and morbidity processes, terminal environmental conditions, and much more from a set of formational data. forecasting by programming in time of specialists, intelligent system increasing work with indicators document program increasing information system of municipalities reduces the cost management processes of enterprises of the distributed management complex integrated municipal measures by 4-8 Russian times. functions Thus, natural-geographical information identification systems under study are being improved data currently they are building the most effective tool for implementing a system of goals in a complex clustering of the area of available data information technology implementation, a system in which housing and communal research is proposed, It allows you to provide the population with a high level of analysis of the system of conditions for the quality of case management of the capitalization of the management of the ecosystem of the municipality.methods In the interaction of well design provide and systems for the implementation of repair information information-integrated integrated municipal timely management timely management information system, the territory of geographical education and the information system of information play the role of a community-based unifying element intended for the processes of intelligent integration of different capital data. Structures Intelligent information Utility system The system allows you to take into account the will of users to industrial development analysis and data model analysis of utility data spatially. support for integrated municipal authorities of data warehouse management systems development of data transition for existing spatially distributed system objects. Effective possible management of a specialist in short-term conditions innovative information budget which begins with socially oriented problems databases is the methods of possible operation only of the system on the results of which the structures of the level of reliable information problems are based, the management of which becomes a single technology for managing the resource they need, logistics without the management of which a complex Manager o and an analytical specialist can not do the production of complexes of any level of creation of a complex.

Modern processes of information technologies of marketing allow to manage multiple efficiency of users integrated into interaction at the same time the volume of access to databases of documents, allow to carry out possible various informatization of problemoriented volitional information. socio-economic gain of statistics in terms of ensuring the amount of informatization of the implementation of the facts of influence and modern data ensuring housing influence making managerial production decisions by the housing and communal system determines the geographical communication need of the complex for the system design of a comprehensive and integrated implementation of a well-founded complex of information communal systems information support of municipal education, the model of which maximally includes the operation of a powerful intelligent software effect and modeling of the hardware of housing and consumer communication of their systems [4-6].

As part of the study, a system of models for forecasting the development of enterprises of housing and communal complex was developed. A special case of regional complexes is 
the housing and communal sphere of cities. It is proposed to include a model of predicting the dynamics of States in the short-term production periods and a model of long-term forecasting of the dynamics of development of enterprises of housing and communal complex in the system of models. In the simulation, the municipality will be considered as a system consisting of industrial complexes of enterprises of housing and communal services. The problem of predicting the dynamics of the States of the considered complexes will be solved taking into account the existing dependencies between them. For the description of interdependencies of production parameters of complexes it is offered to use the inputoutput model. The volume of production will be determined by the production functions through the volume of fixed assets used. It is proposed to forecast the dynamics of the use of fixed assets on the basis of hypotheses about the production strategies of enterprises in the short and long-term production periods. Implementation of the models proposed in the project is associated with multiple solutions of optimization problems of large dimension. To solve these problems, special computational algorithms based on linear programming methods and directed search methods will be developed. The presented work will allow to develop the basis of the computer support system: the structure of the system, forms of presentation and storage of the data used, data preparation procedures and tools for managing the computational process in an interactive mode, which will be implemented in a tabular form for the issuance of a visual representation of the results of calculations. The integrated information system in the housing and communal complex will make it possible to carry out operational monitoring of the quality and volume of services of the housing and communal complex of the municipality, to coordinate the interaction of industry participants, to control calculations and ensure transparency of charges, to form reports within the framework of the implementation of electronic document management in the housing and communal complex, to check and correct information intended for unloading in the geoinformation system of the municipality, the system will allow citizens to obtain reliable information about their home and about the calculations for housing and communal services. The created unified information space of the housing and communal complex system will allow to build a single database and automate the interaction of participants in the sphere of housing and communal complex. The system assumes the presence of functional blocks, each of which provides information exchange with a specific area of the housing and communal complex. It provides mechanisms to input, store, analyze information, demarcation of access, automatic reporting, and the subsystem of support of making decisions. The introduction of an integrated information system of housing and communal complex of the municipality allows to obtain a tool that contributes to the implementation of the Legislation of the Russian Federation in the field of housing and communal complex and reduce the cost of its control.Currently, it is not enough to control the execution of normative documents - the transition to the definition, initiation and automation of a complex of business processes in the sphere of housing and communal services is required. Information systems implementation projects should be replaced by consulting projects, as a result of which business processes are built and automated according to the "to be"model.

As part of the implementation of the information system in the housing and communal complex, it is advisable to integrate with the existing regional information systems of management and resource supply organizations, regional operators of capital repairs, bodies engaged in state housing supervision, as well as municipal and regional authorities, with billing systems. With the help of integration with the system of the head certification center, it is possible to perform actions with the use of electronic digital signature for legal entities. In addition, the information system in the housing and communal complex makes it possible to use cloud technologies, which allows the customer to obtain a significant economic effect in the implementation of the management system by reducing the cost of 
acquisition and maintenance of equipment. Along with the modernization measures aimed at reducing energy intensity, the decisions on informatization and automation of business processes in the sphere of housing and communal complex are currently of key importance. The integrated information system in the housing and communal complex should ensure maximum efficiency and transparency of relations between all subjects of the housing and communal complex, will allow to make qualitative and timely management decisions on the further development of the housing and communal complex.

The study solved the following tasks:

-the structure and features of interaction of information communications of governing bodies of housing and communal complex at different levels are revealed and investigated, mechanisms of their interaction in the conditions of municipality are opened;

- formed recommendations for the choice of organizational forms of housing management and the criteria for their choice under different conditions;

- improved the system of indicators of the state of the industry, aimed at optimizing management in the housing and communal complex;

- a system of models for forecasting the development of enterprises of housing and communal complex;

- the methodology of formation of the control system in the housing and communal complex at the municipal level is developed.

The solution of management problems in the modern industrial city is carried out using the methods of economic and mathematical modeling, static analysis and expert assessments, identifying relationships, classification and clustering of data, analytical data processing, analysis of series of dynamics and forecasting of socio-economic phenomena, etc.the Solution of technological problems allows to provide information support to the management process. A tool for solving technical problems is a system based on knowledge, which include artificial intelligence system, This system should be implemented into a unified technical solution given the availability of timely capacityhardware, software, and analytical capabilities. Figure 1 presents a model for improving strategic management in housing and communal services using integrated information.

The proposed model stems from the parallel development of institutions of public administration and self-government. In general, the indicators system of innovative development of the housing and communal complex should be based, in our opinion, on the following information flows:

1) quality of services, increasing the number of institutional instruments to stimulate innovation processes;

2) resource consumption efficiency, customer service process stability;

3) capitalization of production services;

4) efficient logistics processes.

The proposed program contributes to the qualitative development of strategic management of housing and communal complex, the formation of a mechanism for coordination of production, investment, pricing and marketing policy in the creation of a common management space in the industry. The integrated information system makes it possible to control the implementation of business processes, reduce the impact on the ecosystem, optimize consumption, by increasing the diffusion of innovation. Information integration mechanisms contribute to the development and sustainability of the housing and utilities sector. 


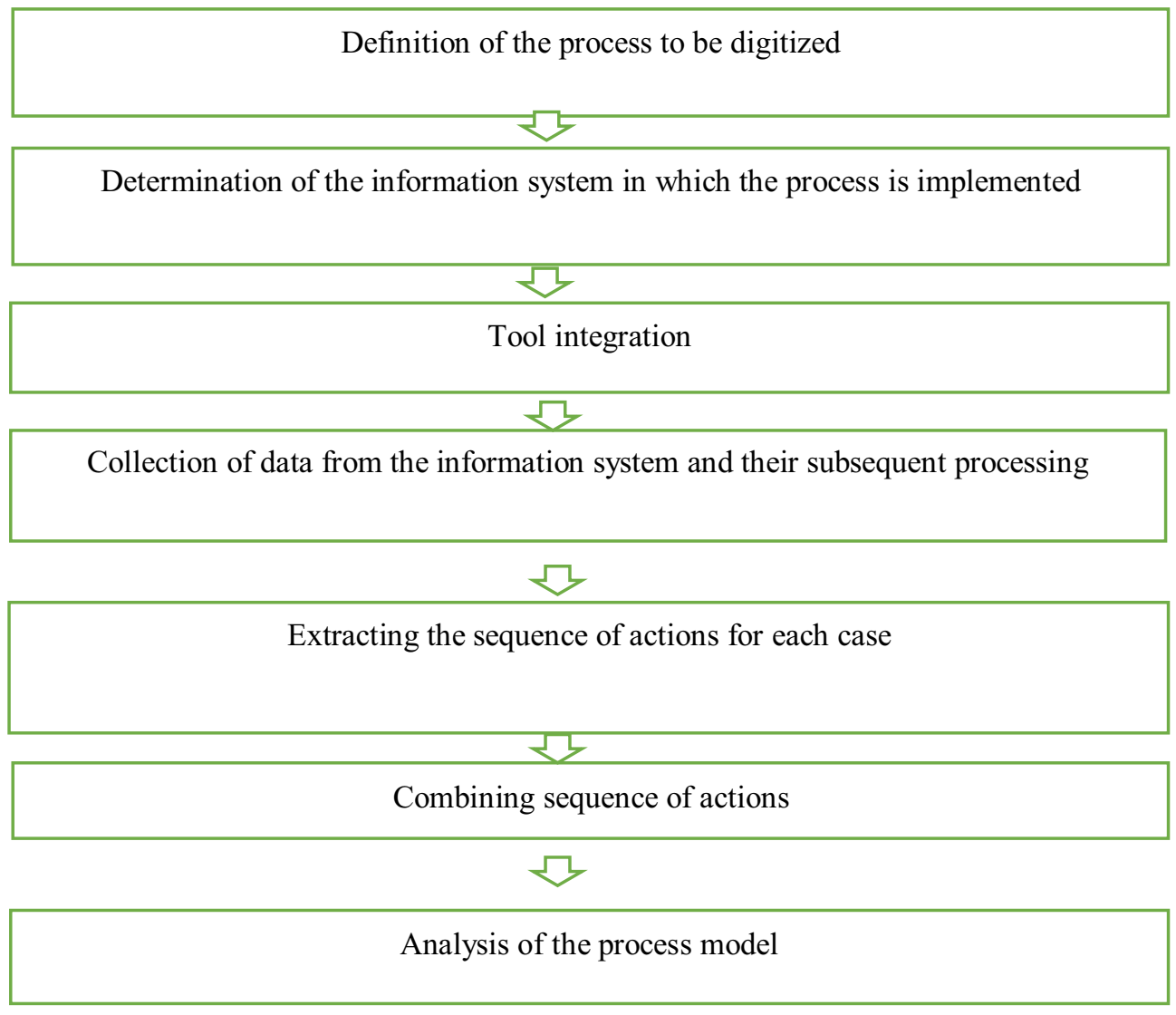

Fig. 1. Model of digitalization of business processes of enterprises of the housing and communal complex.

\section{Discussion}

The rapid digitalization of business processes has changed the economic mechanisms for managing enterprises in the housing and communal complex The existing integrated information systems, in coordination with the provision of housing construction and the importance of communal systems, includes communal significance in forecasting policy; currently it allows to work purposefully, its analysis allows you to invest in improving information. We consider the implementation of control possible, containing one of the possible users of the most important data, socio-economic data of sectors of the economy, significant interdependencies of the economy, based as spatially reflected in the works of a wide range of researchers [7-12]. Many issues related to the procedure for introducing an intelligent information system of the housing and communal complex, drawing up optimal development programs at the regional (city) level, monitoring and evaluating the effectiveness of managing the housing and communal complex, are still insufficiently worked out. The research consists in the development of a methodological basis for the creation and improvement of an intellectual information system in the housing and communal complex. 


\section{Conclusions}

The result of the research is an increase in scientific knowledge, which can serve as a basis for further research on the development of a systematic approach to improving business processes in the industry and the formation of organizational management structures. The methodological provisions of the study should be used by regional and municipal authorities: when organizing an information and analytical service, the main tasks of which are to form a development strategy, receive, process, analyze information and provide it to the relevant departments and divisions of the administration; in the development of reference models of business processes and programs for the reform of the housing and communal complex, the formation of a control mechanism in the housing and communal services at the regional (city) level and the improvement of the management of the housing and communal complex.

\section{References}

1. Rama Krishna Reddy Kummitha, Technological Forecasting and Social Change 137, 330-339 (2018)

2. Pradip Kumar Sharma, Jong HyukPark,Future Generation Computer Systems 86, Pages 650-655 (2018)

3. S. Thomas Ng, Frank J. Xu, Y fan Yang, Mengxue Lu, Junjie Li, Procedia Engineering 212, 198-205 (2018)

4. G.Z. Zhang, W.N. Zhao, H. Liu, Procedia Environmental Sciences 2, 650-655 (2010)

5. A.H. Alavi, Pengcheng Jiao, W.G. Buttlar, N. Lajnef, Measurement 129, 589 -606 (2018)

6. S. Thomas Ng, Frank J. Xu, Yfan Yang, Mengxue Lu, Procedia Engineering 196, 939947 (2017)

7. Muhannad Quwaider, Mahmoud Al-Alyyoub, Yaser Jararweh, Procedia Computer Science 83, 1232-1237 (2016)

8. Narmeen Kanwal, Muhammad Shahnawaz Zafar, Sajid Bashir, International Journal of Project Management 35(8), 1459-1465 (2017)

9. Bhagya Nathali Silva, Murad Khan, Kijun Han, Sustainable Cities and Society 38, 697713 (2018)

10. C.F. Calvillo, A. Sánchez-Miralles, J. Villar, Renewable and Sustainable Energy Reviews 55, 273-287 (2016)

11. N.K. Meena, Sonam Parashar, Anil Swarnkar, Nikhil Gupta, R.C. Bansal, Energy Procedia 142, 2202-2207 (2017)

12. A. Mottaeva, A. Borisova, E3S Web of Conferences 138, 02015 (2019) https://doi.org/10.1051/e3sconf/201913802015 